\title{
A statement on attendance of Health Authority Officers at Consultants' Advisory Appointments Committees
}

One of the recommendations in NAHA's evidence to the Prime Minister's Review was that District General Managers should take part in the Consultant Appointment Committees in assessing consultants managerial ability. This matter has been discussed at the Joint Consultants Committee with the DHSS and it is quite clear the present guidelines are that the Manager and other Officers of the Authority cannot participate in Appointment Committees.

This has been clarified in a letter from the DHSS to General Managers of Regional Health Authorities, dated 28 September 1987 [DA(87)46], as follows:

"The NHS (Appointments of Consultants) Regulations 1982 set out clearly membership of such committees, oblige the RGM to provide such clerical or other assistance as the Committee may require, and lay down that the procedure of the Committee shall be such as the members of the Committee think fit. The Committee can, therefore, request the assistance at their meeting of any officer, whether of the RHA or of the DHA in which the selected consultant will be working, but the attendance of any non-member at the meeting can only be in accordance with the wishes of the Committee. Circular $\mathrm{HC}(82) 10$ states that the chairman of the AAC can issue the invitation. It is however clear from the Regulations, which of course reflect the formal legal position, that the Chairman does not have the power to act alone in this respect and may issue such an invitation only if it is the wish of the majority of the members of the Committee.

The AAC procedures aside, it is likely that potential candidates for consultant posts and senior managers in health authorities would welcome the opportunity to discuss matters of common interest (for example, local plans for service developments, likely availability of manpower and other resources). Such meetings might form a natural part of the programme when potential candidates visit the District(s) in question in order to meet their potential future consultant colleagues and to familiarise themselves with the locality and its health facilities."

If members of the College are asked about the attendance of a Manager at an Appointments Committee, they should state very clearly that the Manager should be available to the Committee, before the actual interviewing process begins to discuss any particular details about the facilities available for the post which require clarification. The Manager should not be present when the interviewing and selection process is taking place.

Dr J. L. T. BIRLEY

This statement, prepared by the President, was approved by Council at its meeting on 17 January 1989.

\section{Obituary}

Editor: Henry R. Rollin

\section{Anthony Clare Fairburn, Consultant Psychiatrist; Department of Child and Family Psychiatry, Royal United Hospitals, Bath}

Anthony Clare Fairburn - Tony - as he was known to his many friends, died suddenly at the age of 61 on 3 October 1988 while at work in his Department.

Tony was born in Singapore where his parents were working with the Colonial Service. He was educated in this country and qualified from St Mary's Medical School, London, in 1951. After his call up for military service, he requested a posting to Malaysia, where at that time British troops were actively engaged in fighting a guerilla enemy. His work as a junior specialist included the medical care of a Gurkha unit and it was typical of his careful, thorough approach that he not only took pains to learn Gurkhali, but also published a Handbook of
Medical Gurkhali which has been extensively used. This interest continued throughout his life and he made two specialist advisory tours in Pakistan on behalf of the British Council in 1985 and 1986. He was considering a third such invitation at the time of his death.

On his return to this country he decided upon a career in paediatrics and early in his training he became concerned with the emotional and social aspects of childhood illness. He therefore sought further training in child psychiatry at Great Ormond Street and Queen Charlotte's Children's Hospitals and later at the Maudsley Hospital. He was then appointed to registrar posts at Glenside \& Barrow Psychiatric Hospitals Bristol and to Bristol Children's Hospital. The consultant post which he held until the time of his death was a joint post in child psychiatry and mental handicap. 
Bristol became his home and Bath the area in which he created the highly esteemed Department of Family Psychiatry at the Royal United Hospitals. In the field of mental handicap he worked with the Hortham and Brentry Group of Hospitals but, as in his work in child psychiatry, his particular concern was the development of community services, building up a much valued counselling and assessment service.

He was an acknowledged expert in the now much publicised field of child abuse and, as early as 1970 , helped to found one of the first child abuse centres in this country. He wrote a number of papers on this problem from 1977 onward. He gave evidence before the DHSS working party on child care law, and was a member of a Royal College of Psychiatrists' working party considering the law on infanticide.

He held the appointment of Clinical Teacher with the Universities of Bath and Southampton. His clinical and academic achievement was acknowledged by the award of Fellowships by both the Royal College of Physicians and the Royal College of Psychiatrists.

Tony was much esteemed by his colleagues and many friends, and was closely involved in local child psychiatric committees. He was an active sportsman. An early interest in mountaineering had to give way to the responsibilities of professional and family life, but he maintained a continuing interest in hill walking which he was still able to enjoy on his last summer holiday. Ice skating became a great enthusiasm, and he was a skilled performer. In what little spare time remained, with the help of his family, he renovated and sailed his narrow boat.

He leaves a devoted family, Margaret his wife, five children and grandchildren.

WLW

Ulrich Paul Seidel, Community Psychiatrist, Harringay Health Authority, North East Thames Region

Dr U.P. Seidel, formerly a community psychiatrist in Haringey, London, died on 15 September 1988, aged 68.

Ulric Paul Seidel was born in Berlin and in 1935 left Nazi Germany with his parents. Eventually the family settled in Australia and after the war he graduated with distinction at Sydney University. He worked in general practice until 1962 when he and his widowed mother came to London where, after further postgraduate study, he obtained psychiatric qualifications. The last 20 years of his working life were spent in psychiatry, at first with the Middlesex County Council and later with its successor in Haringey.

Dr Seidel was an early enthusiast and advocate of community psychiatry, and his interests ranged widely, from neuropsychiatry to group psychotherapy. He was a gifted clinician, but his most outstanding characteristic was his kindness and exceptional devotion to the care of his patients.

$\mathrm{He}$ is survived by his wife Vivienne whom he married in 1985.

AGM

\section{WaClaw Wollen MBE, formerly Consultant Psychiatrist, Darenth Park Hospital, Kent}

Friends and colleagues of Ken Wollen will be saddened to learn of his death on 31 August 1988 following a prolonged period of ill-health, the last 18 months spent in hospital. He was born in Poland and qualified in medicine at Warsaw University 1935 . He served in the Polish Army from 1929-49, gaining distinction as an officer in the Polish Army Medical Corps which came under British command after 1940. He saw action in the Polish Armoured Division and received decorations including the MBE for war services.

In 1945 he joined the Colonial Medical Service in Grenada and subsequently returned to pursue a career in public health and psychiatry, obtaining the DPM in 1957. As former Deputy Medical Superintendent and Consultant Psychiatrist at Darenth Park Hospital until his retirement in 1974, he took a particular interest in mentally handicapped children and their families. He established a renowned Children's Unit at Goldie Leigh Hospital with combined psychiatric/paediatric clinics which served as a model until the community care movement arose which sought to remove mentally handicapped children from residential hospital care. He also pursued a special interest in mentally impaired offenders, adding the DMJ to his qualifications in 1964.

He served on the Mental Health Review Tribunal and participated actively in hospital administration as chairman of various committees. He took part with the greatest enthusiasm in the training of doctors and nurses, especially in medical aspects of mental handicap. He collected a notable library of literature on mental deficiency, mental subnormality and mental handicap, reflecting changes in perception of the subject.

Ken Wollen viewed future developments in his field with some misgivings, being of the generation which saw merit in one specialist maintaining continuity of support and overall responsibility for a handicapped patient from early childhood into adulthood. This was undoubtedly valued by families who kept in regular contact over decades. He was involved in planning for the reorganisation of local hospital services, but some projects which he advocated were ultimately swept away in the vogue for community care in which psychiatry was to play a reduced part. His death coincided with the closure of Darenth Park Hospital, to which he had devoted the latter years of his varied medical career.

PGW 